\title{
Research Article \\ Study on Gas Control in Goaf of High Gas Coal Seam: A Case Study of Tingnan Coal Mine, China
}

\author{
Jiamei Chai \\ China Coal Research Institute, Beijing 100013, China \\ Correspondence should be addressed to Jiamei Chai; cjm1175747273@163.com
}

Received 14 December 2021; Accepted 12 February 2022; Published 1 March 2022

Academic Editor: Yanan Gao

Copyright ( 2022 Jiamei Chai. This is an open access article distributed under the Creative Commons Attribution License, which permits unrestricted use, distribution, and reproduction in any medium, provided the original work is properly cited.

\begin{abstract}
When stratified mining is used in extrathick coal seam, the gas emission in goaf of the first mining face is large, and it is easy to cause gas overrun in the upper corner during the rapid advance of the working face, which seriously affects the safe and efficient mining of the working face. The gas drainage in goaf by roof high-drainage way is the fundamental solution to solve the gas overrun in the upper corner, and the reasonable layout position is related to the drainage effect of high-drainage way. In this paper, 206 slicing mining face of Tingnan Coal Mine in Binchang Mining Area of Shaanxi Province is taken as an engineering example. Theoretical analysis, fluent numerical simulation, and field verification are used to study and analyze the reasonable layout position and drainage effect of roof high-drainage way in working face. The research results show that the reasonable position of the high-drainage way layout is the horizontal distance of $15 \mathrm{~m}$, the vertical distance of $21 \mathrm{~m}$ and $26 \mathrm{~m}$, the horizontal distance of $25 \mathrm{~m}$, and the vertical distance of $21 \mathrm{~m}$ and $26 \mathrm{~m}$. In the layout position of $15 \mathrm{~m}$ horizontal and $21 \mathrm{~m}$ vertical, the gas drainage volume of high-drainage roadway is $16.4 \sim 23.3 \mathrm{~m}^{3} / \mathrm{min}$, and the average gas drainage volume is $20.45 \mathrm{~m}^{3} / \mathrm{min}$. The gas drainage volume of high-drainage roadway accounts for $52.1 \%$ of the gas emission, which achieves the expected effect and realizes the safety requirements of gas prevention and control in working face. The research results of this paper can provide guidance for the layout of high-drainage way in Tingnan Coal Mine and adjacent mines.
\end{abstract}

\section{Introduction}

Coal is one of the most important energy sources for China's economic and social development [1-5]. At the same time, the coal industry is the industry with the most frequent disasters and the most serious casualties, especially the gas accident [6-10]. High gas extrathick coal seam has the characteristics of high gas content, high mining intensity, and fast advancing speed, which is easy to cause gas overrun in the upper corner, restricts the advantages of working face, and poses a great threat to safety production [11-13]. Coal mine gas drainage is the most effective means of gas disaster prevention, and the high-drainage way drainage method is one of many gas drainage methods. It has the characteristics of long extraction time, large extraction radius, high extraction purity, and simple extraction system, which can greatly reduce the gas emission from goaf to working face. At present, the layout of high-drainage way in coal mine site is mostly carried out according to experience, lack of system- atic theoretical guidance, it is difficult to determine the reasonable layout position of high-drainage way in order to achieve better drainage effect, and high-drainage way is also a project investment that needs to consume huge manpower and material resources. If it cannot play its role well, it is bound to cause waste and loss of resources. Therefore, the determination of reasonable layout position of highdrainage way has important practical value in coal mine production process.

The study on the strata deformation and failure law gas migration law in goaf during mining has important guiding significance for determining the reasonable layout position of high-drainage way. Qian Minggao and Professor Xu Jialin et al. $[14,15]$ studied the distribution law of moving fractures in rock strata based on the theory of key strata, revealed the two stages of mining bed separation change of overburden strata in longwall face, and pointed out that there is a bed separation development area which is horizontally connected along the goaf, that is, the distribution 
characteristics of "O" shaped circle of mining fractures. $\mathrm{Li}$ Shugang and Lin Haifei [16, 17] describe the distribution of fracture zone accurately by analyzing the movement law of key strata after mining, put forward the theory of mining fracture "elliptic paraboloid," and give the mathematical calculation parameters of elliptic paraboloid. According to the "O" compaction characteristics of goaf caving body, Professor Li Zongxiang gives the model expression of roof rock caving and the "O" circle model of goaf caving expansion coefficient distribution, which makes the goaf gas migration and simulation closer to the real situation [18]. Based on the research on the deformation and failure law of gob-covered rock and the gas migration law in gob, many scholars have studied the application of high-drainage roadway in coal mines. Yuan Liang, Liu Zegong, and Dai Guanglong [19-21] put forward the layout principle of the reasonable position of the roof high-drainage roadway and the highlevel borehole according to the distribution characteristics of the overburden fracture and the formation process of the "O" circle and explored the drainage practice of the high-drainage roadway in Huainan and other mining areas. Lou used UDEC discrete element simulation to analyze the collapse and deformation characteristics of high pumping roadway and analyzed the floor heave mechanism and support of high pumping roadway [22]. However, there is a lack of research on the influence of mining overburden failure law and stope gas migration law on the layout of highdrainage way and the principle of high-drainage way extraction during stratified mining of extrathick coal seams. At the same time, there is a lack of intuitive evaluation and comparison of the extraction effect of different layout positions of high-drainage way.

In view of the above analysis, in this paper, we analyzed the law of deformation and failure of goaf rock and the law of gas migration in goaf during stratified mining of extrathick coal seam. Through theoretical analysis, we clarified the distribution characteristics of mining fracture "O" circle formed by deformation and failure of mining rock and explained the principle of high-drainage way drainage. The layout range of high-drainage roadway was determined by theoretical calculation and actual measurement of "two zones" height. On this basis, the layout position of highdrainage way was further studied by numerical simulation, and the best position of high-drainage way was determined. Good results were achieved in actual extraction, which effectively eliminated the gas overrun accident in the upper corner and ensured the safe and efficient mining of the working face. The research process and results can provide practical guidance for the application of high-drainage way layout in Tingnan Coal Mine and adjacent mines.

\section{Engineering Background}

Tingnan Coal Mine is located in Changwu County, Xianyang City, Shaanxi Province, and its location is shown in Figure 1. 4\# coal seam is the only coal seam in Tingnan Coal Mine, the general depth is $+500 \sim 700 \mathrm{~m}$, the coal seam thickness is $1.00 \sim 23.24 \mathrm{~m}$, and the average thickness is $11.05 \mathrm{~m}$. The 206 working face is located in No. 4 coal seam. The working face is $200 \mathrm{~m}$ long, the advancing length is $2199 \mathrm{~m}$, the average dip angle is $4^{\circ}$, the average thickness is $18.35 \mathrm{~m}$, and the mining thickness is $6 \mathrm{~m}$, as shown in Table 1. Coal seam structure is simple, stable occurrence, which belongs to hard permeability coal seam, gas desorption fast. The absolute gas emission of the working face is $40.29 \mathrm{~m}^{3} / \mathrm{min}$, and the absolute gas emission of the goaf is $27.12 \mathrm{~m}^{3} / \mathrm{min}$, accounting for $67.3 \%$ of the gas emission of the working face. Therefore, the treatment of gas in the goaf is an inevitable safety problem in the mining of working face. It is necessary to seek appropriate control measures to reduce the gas content in the goaf and ensure safe production according to the law of gas migration and accumulation in the goaf.

\section{Theoretical Analysis of Gas Control in Goaf}

\subsection{Rule of Overlying Strata Damage in Goaf. According to} the classical mine pressure theory [23], after the coal seam mining, the coal and rock around the stope are divided into vertical and horizontal zones according to the stress-strain change, failure characteristics, and spatial-temporal relationship. In the vertical direction, the roof strata are divided into falling zone, crack belt, and bending subsidence belt according to the failure characteristics and caving law. In the horizontal direction of fractured zone, it is divided into coal wall support influence zone, strata separation zone, and recompaction zone, as shown in Figure 2. The division of vertical "three zones" and horizontal "three zones" in goaf is of great significance to the study of gas migration distribution and pressure-relief gas drainage in goaf.

According to the prediction empirical formula of the maximum height $H_{c}$ of falling belt and the maximum height $H_{f}$ of fracture zone, the empirical formula (1) of medium hard rock is selected for the height calculation of caving zone and the empirical formula (2) of soft rock is selected for the height calculation of fracture zone. It can be calculated that the height range of falling belt is $10.15 \sim 14.91 \mathrm{~m}$, and the height range of crack belt is $21.42 \sim 29.42 \mathrm{~m}$.

$$
\begin{gathered}
H_{c}=\frac{100 \sum M}{4.7 \sum M+19} \pm 2.2, \\
H_{L}=\frac{100 \sum M}{3.1 \sum M+5.0} \pm 4.0 .
\end{gathered}
$$

With the continuous advancement of the working face, the overlying strata will form two types of fractures: the vertical fractures perpendicular to the level and the separated fractures between the layers (along the layer fractures). The through-layer fractures connect the adjacent upper and lower strata, providing a channel for the flow of gas between the layers. The bedding fractures are caused by the expansion deformation of rock strata, which is helpful for gas desorption and bedding flow. According to the previous analysis, in the regular falling belt and crack belt, the serious fracture area of rock strata is the extremely developed area of vertical cracks at the vertical level. In the fractured zone, the general fracture area of rock strata is the coexistence area of 


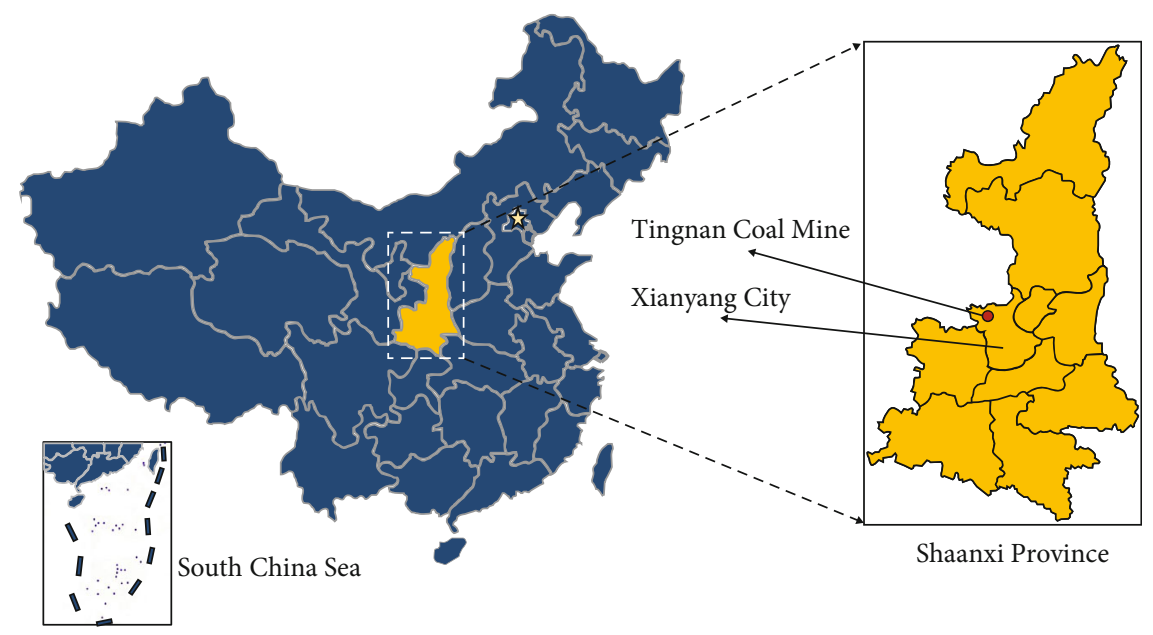

Figure 1: Location of Tingnan Coal Mine, Shaanxi Province, China.

TABLE 1: Situation of coal seam in 206 working face.

\begin{tabular}{lccccc}
\hline Thickness $(\mathrm{m})$ & Texture & Dip angle $\left(^{\circ}\right)$ & Recoverable coefficient & Variation coefficient & Stable degree \\
\hline$\frac{16.5 \sim 20.2}{18.35}$ & $0.58(0.16) 0.42(0.18) 17.76$ & $\frac{0 \sim 6}{4}$ & $100 \%$ & $9.6 \%$ & Stale \\
\hline
\end{tabular}

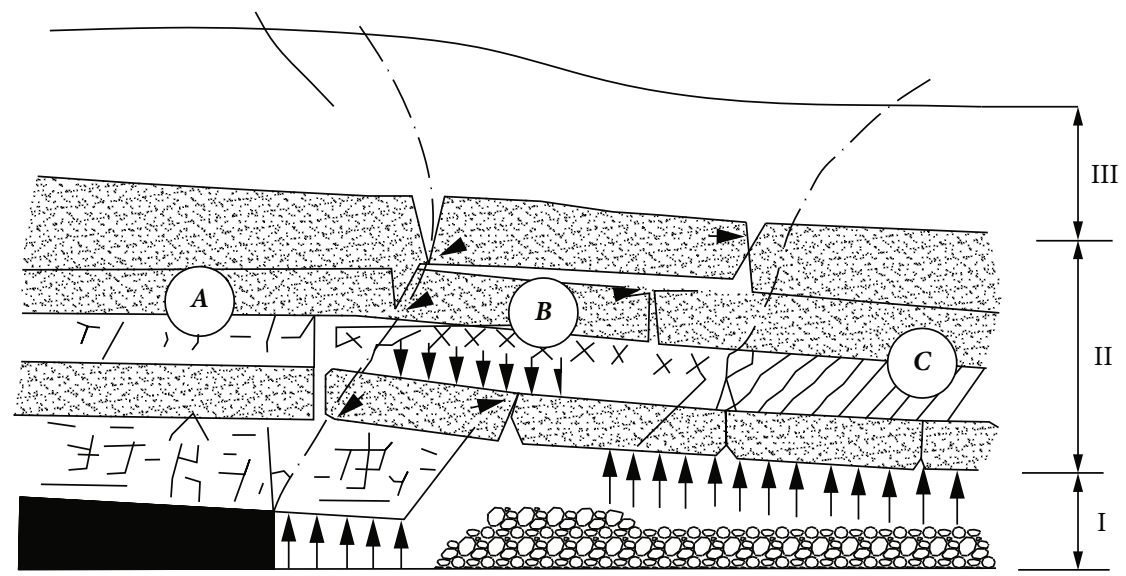

FIGURE 2: Influenced trait of strata damage characteristics. I: falling belt; II: crack belt; III: bending subsidence belt; A: coal wall support influence area; B: strata separation zone; C: recompaction zone.

vertical cracks (through-layer cracks) and along-layer cracks, and on this basis, the development of along-layer cracks is the main one.

The caving zone and fracture zone of the 206 working face were measured by the borehole return water metering method. The study is shown in Table 2, and the measured results have a guiding role in the height judgment of "two zones" in the 206 working face.

3.2. Gas Migration Law in Goaf. When coal seam and surrounding rock gas are not disturbed by mining engineering, they usually exist in a free state and adsorption state. When the mining engineering destroys or disturbs the coal seam, the deformation, movement, collapse, and destruction of the surrounding rock (coal seam) of the stope will break the occurrence state of gas in the coal seam. After the coal seam mining, the permeability of coal and rock strata in the mining fractured zone is greatly increased, and the gas in the coal seam and adjacent layers can be desorbed and transported, which is the channel and space for gas flow and reservoir.

The gas distribution in the working face during the mining of working face 205 was also analyzed. The distribution of gas concentration along the mining length direction was monitored on site, and the results are shown in Figure 3. In the working face from the intake roadway to the middle of the mining face before $100 \mathrm{~m}$ within the scope of gas concentration change is not big, the average concentration is less 
TABLE 2: Theoretical calculation and test results.

\begin{tabular}{lcccc}
\hline \multirow{2}{*}{ Coal seam } & \multicolumn{2}{c}{ Height of fall belt $(\mathrm{m})$} & \multicolumn{2}{c}{ Height of crack belt $(\mathrm{m})$} \\
& Theoretical value & Actual inspection value & Theoretical value & Actual inspection value \\
\hline 4 & $10.51 \sim 14.91$ & $14.4 \sim 21.4$ & $21.42 \sim 29.42$ & $21.4 \sim 40.3$ \\
\hline
\end{tabular}

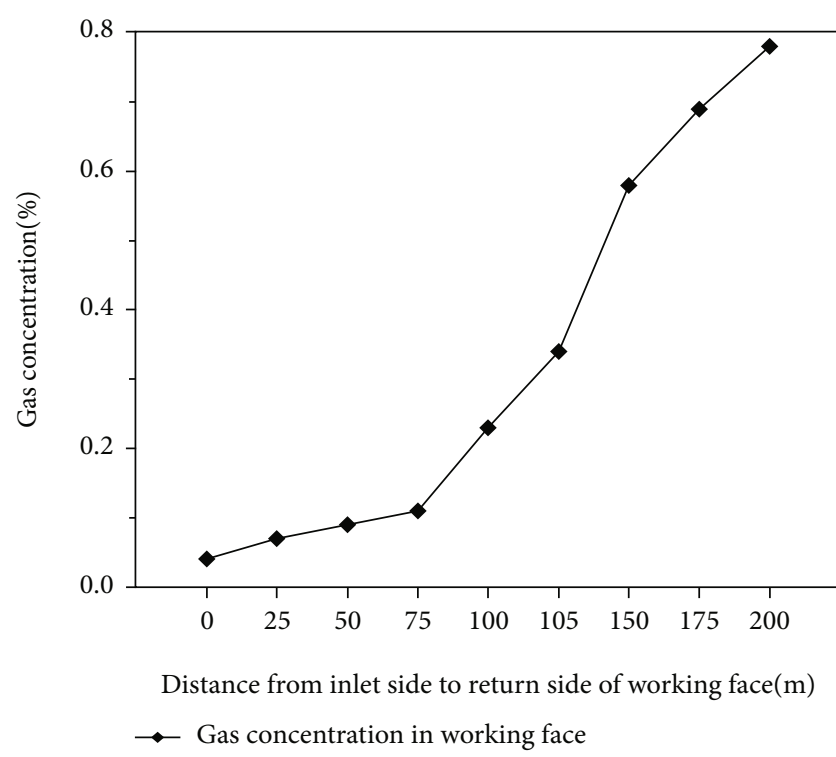

Figure 3: Gas concentration distribution lies in the working face.

than $0.1 \%$; after $100 \mathrm{~m}$ of working face, the gas concentration in return airway increased rapidly, especially in the range of $30 \mathrm{~m}$ near the return airway, which was at a high level, reaching nearly $0.8 \%$. The long working face length and high strength production caused great difference in gas concentration between the inlet side and the return airway.

Four groups of positions of $50 \mathrm{~m}, 100 \mathrm{~m}, 150 \mathrm{~m}$, and $200 \mathrm{~m}$ were selected along the vertical mining direction. Four test positions were selected in the vertical working face direction of each group: position 1 was the coal wall, position 2 was the upper part of the scraper, position 3 was the front position of the support column, and position 4 was the tail of the support, see Figure 4 . It can be seen from the figure that the gas concentration of each group of tests from position 1 to position 3 shows a distribution trend from high to low and then increases, and the gas concentration of position 3 is lower than that of other positions. Secondly, the tail of the support near the goaf is higher and grows faster along the mining length direction, which shows that the gas in the natural accumulation area of the caving gangue near the working face also has a tendency to migrate to the leeward side under the action of wind flow.

\subsection{Determination of Layout Range of High-Drainage Way.} After coal seam mining, the natural equilibrium state of coal and rock around the stope is destroyed, and the mining fracture "O" circle distribution is formed along the strata above the goaf, as shown in Figures 5 and 6. The separation rate of strata in this area is high, and a large amount of gas gathers

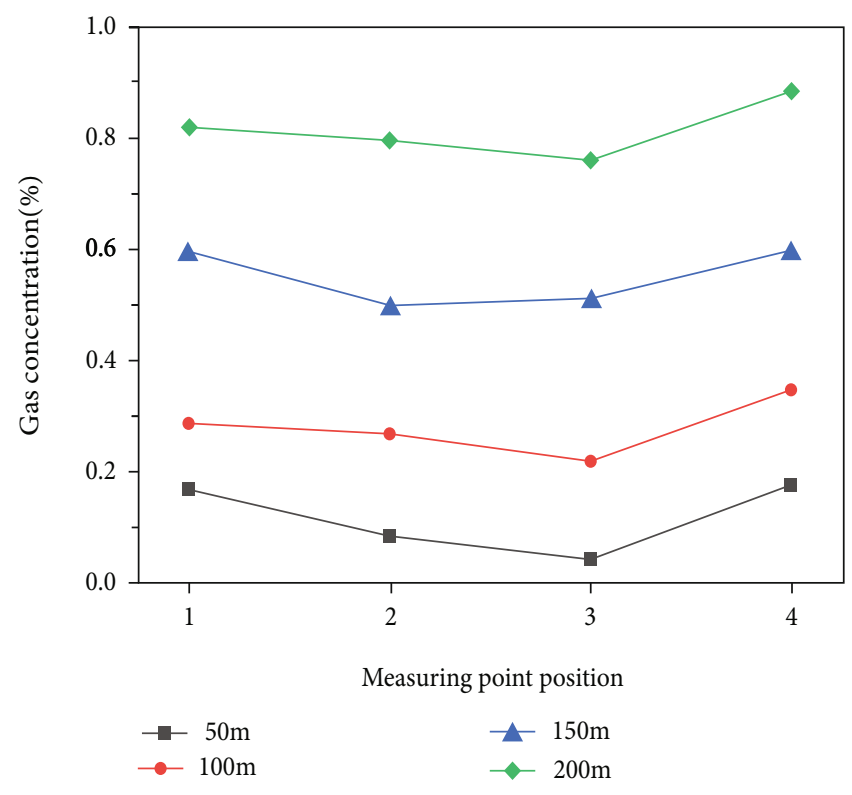

FIgURE 4: Gas concentration distribution vertical working face.

in this narrow and long area. Under the action of wind pressure and gas concentration difference, it slowly diffuses outward to form a gas river. The fracture cracks developed in the near working face will roughly form an "O" type circle distribution along the roof direction in the upper part of the working face. The permeability of coal and rock mass is greatly increased by cross-layer fracture, which becomes a natural channel for gas desorption and migration in adjacent layer and coal seam under the influence of pressure relief caused by mining disturbance. Therefore, the layout of gas drainage way in this area will be most conducive to the gas inflow into the working face in the drainage roadway's intercepting gas conduction zone. At the same time, it can also effectively change the gas flow field in the goaf, so that the gas in the goaf flows to the drainage roadway under the action of the negative pressure of mechanical drainage and reduces the gas amount flowing into the working face in the goaf.

According to the above analysis of the distribution of rock fracture development zone, the reasonable vertical distance range of high-drainage way layout is from the upper part of the caving zone to the middle and lower parts of the fracture zone. The rock caving angle determines the width of the fracture zone, which provides theoretical guidance for the determination of the extraction distance of high pumping roadway, as shown in Figure 7. According to formulas (3) and (4), the horizontal distance range of high pumping roadway layout can be obtained. 


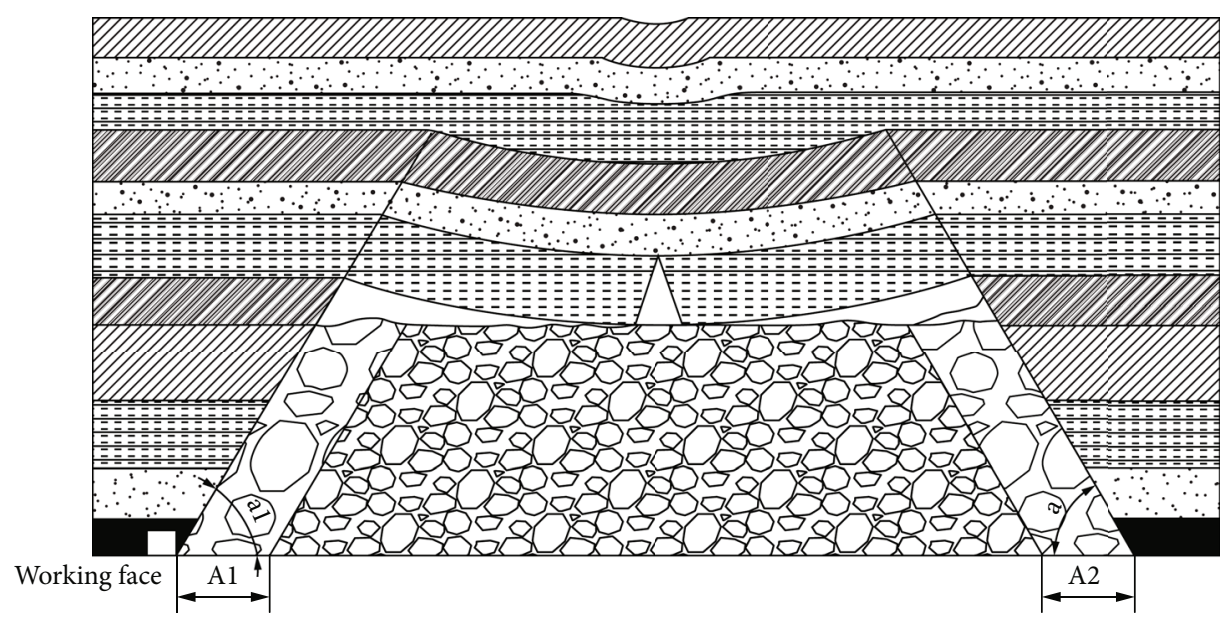

Figure 5: Mining-induced fracture zone alone inclination.

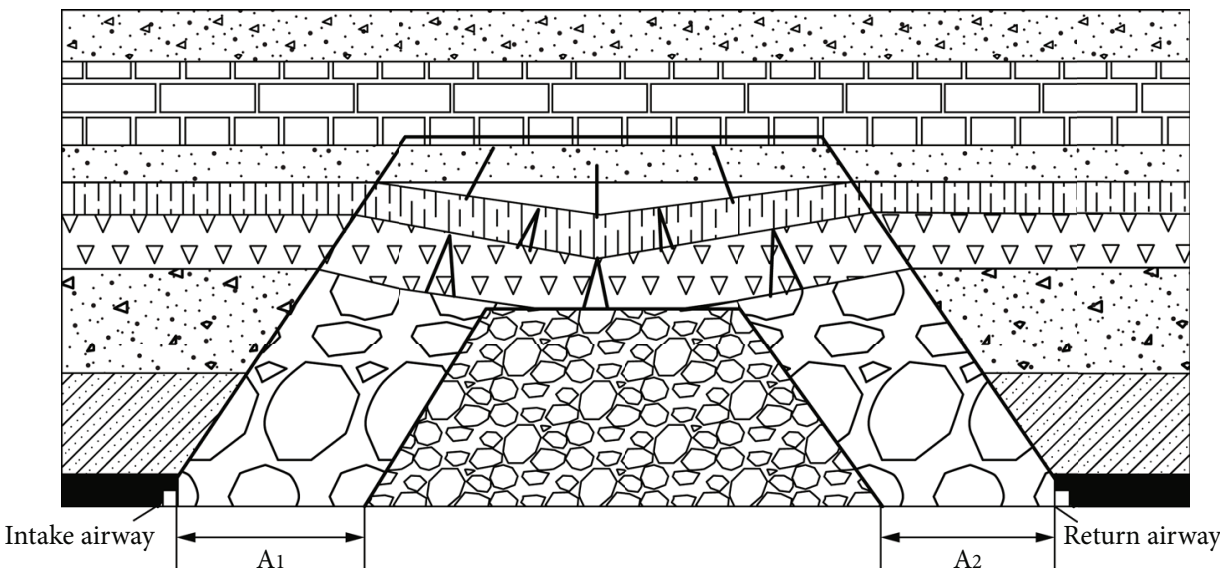

Figure 6: Mining-induced fracture zone alone tendency.

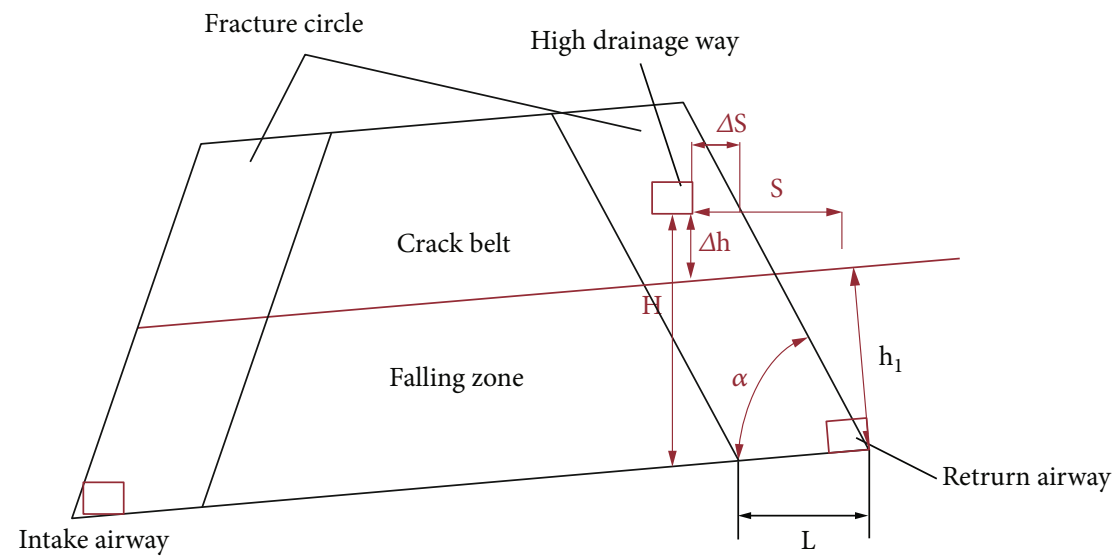

Figure 7: Profile map of inclination high-drainage gas roadway.

$$
\begin{aligned}
& S=\frac{H}{\tan \alpha+\Delta s}, \\
& H=h_{1}+\Delta h .
\end{aligned}
$$

In the formula, $S$ is the distance from the highdrainage way to the return airway; $H$ is the vertical dis- tance of the high-drainage way; $h_{1}$ is the height of the caving zone; $\Delta s$ is the horizontal distance from the side of the high-drainage way to the side of the fissure circle return airway, and the upper limit is the fissure circle bandwidth; $\Delta h$ is the vertical distance from the floor of the highdrainage way to the caving zone, and the upper limit is the maximum height of the fracture development across 
the fracture zone; $\alpha$ is the roof rock fracture angle near the return airway.

According to the actual situation of the 206 working face and engineering analogy, $h_{1}$ takes the measured value as $21 \mathrm{~m}$, and the rock fracture angle is approximately $54^{\circ}$. The ground pressure monitoring results of the 205 working face, the first weighting step distance of the basic roof of the working face is $L_{0}=30 \mathrm{~m}, \Delta s=0.7, L_{0}=21 \mathrm{~m}$, and $S_{\min }=H$ $/ \tan \alpha=15.25 \mathrm{~m}$ is $15 \mathrm{~m}$, so we can get the minimum layout spacing of high-drainage way is about $15 \mathrm{~m}$, and the maximum layout spacing is about $36 \mathrm{~m}$. At the same time, according to the measured data of the height of the falling belt and the crack belt, the vertical layout range of the roof high-drainage roadway is $21 \sim 40 \mathrm{~m}$.

\section{Numerical Simulation of Roof High- Drainage Roadway Extraction}

Through the previous analysis, in theory, an area for the arrangement of high-drainage way has been delineated. In contrast, this is a large area. Whether the high-drainage way of the roof is arranged in this location area can achieve good results in the extraction effect and the gas control in the upper corner. Due to the complexity of the changes in the overlying strata and the inaccessibility of the goaf, it is impossible for the high-drainage roadways of the roof to be tested one by one for verification and analysis. However, numerical simulation analysis can restore the engineering state of high pumping roadway layout to a certain extent. Therefore, this paper uses FLUENT software to simulate and analyze the drainage effect of high-drainage way in different positions in the primary area, so as to determine the reasonable layout position of high-drainage way.

4.1. Numerical Model Establishment and Parameter Selection. First of all, this paper makes assumptions on the problem of gas extraction in goaf by high-drainage way:

(1) It is considered that the goaf is a porous zone composed of coal and rock, and the medium is regarded as isotropic

(2) According to the influence of high-drainage roadway on gas concentration in upper corner and gas in goaf, gas emission in the working face is not considered

(3) The gas in the goaf is considered to be incompressible, and the flow is stable and isothermal

(4) The coal seam dip angle of the 206 working face is $0^{\circ} \sim 6^{\circ}$, and the average dip angle is $4^{\circ}$. The coal seam dip angle can be ignored, and the inlet and return airways are arranged at the same horizontal position

According to the engineering practice of 206 fully mechanized mining face, the model is simplified:

(1) The geometric model is $300 \mathrm{~m} \times 210 \mathrm{~m} \times 52 \mathrm{~m}$; the height of goaf in the model is $40 \mathrm{~m}$, and the lower $12 \mathrm{~m}$ is not mined
(2) The transportation roadway, return air roadway, roof high-drainage way, and goaf of 206 working face are simplified as a cuboid model, ignoring the influence of working face equipment and roof pressure on gas distribution in goaf, only considering the influence of air leakage from fully mechanized mining face to goaf and high drainage roadway extraction on gas distribution and emission in goaf

(3) Set the working face size: $200 \mathrm{~m} \times 9 \mathrm{~m} \times 6 \mathrm{~m}$; intake lane: $20 \mathrm{~m} \times 5 \mathrm{~m} \times 3.5 \mathrm{~m}$; return airway: $30 \mathrm{~m} \times 5 \mathrm{~m}$ $\times 3.5 \mathrm{~m}$; the section of inclined high pumping roadway is $3 \mathrm{~m} \times 3 \mathrm{~m} \times 300$

(4) Since the through-layer fractures in the bending zone are basically not developed, the bending subsidence zone is not considered in the modeling, and the gas flow in the caving zone and fracture zone is only simulated. The height of "two zones" is arranged according to the height of caving zone and fracture zone obtained in chapter 3. The three-dimensional model of goaf in working face is established and meshed by GAMBIT software. The three-dimensional grid plane diagram is shown in Figure 8

According to the actual air supply and model calculation requirements of 206 working face in Tingnan Coal Mine, the inlet roadway is set as the speed inlet boundary, the air volume is $2367 \mathrm{~m}^{3} / \mathrm{min}\left(39.45 \mathrm{~m}^{3} / \mathrm{s}\right)$, and the speed is $2.25 \mathrm{~m} / \mathrm{s}$; air return lane and high drainage way are free exit boundary.

The absolute gas emission of 206 working face in Tingnan Coal Mine is $40.29 \mathrm{~m}^{3} / \mathrm{min}$, and the proportion of gas emission in goaf is $67.3 \%$. The UDF function is used to customize the gas emission source term of goaf to $27.12 \mathrm{~m}^{3} /$ min. The permeability of porous media space is defined by UDF function according to the fracture law of rock caving zone and fracture zone, which is set according to the literature "O" ring distribution coefficient model. In the strike direction, as the distance from the working face is farther, the permeability is lower. In the tendency direction, the permeability gradually decreases from the near trough to the middle of the goaf. In the vertical direction, it increases first and then decreases, as shown in Figure 9.

The high-drainage way in the simulation is also considered according to the porous medium, and the permeability is set according to the different integrity characteristics of the upper part of the caving zone and the fractured zone. In order to be closer to the actual working face, the lower coal seam is set as a gas source item in the goaf.

4.2. Simulation Program. According to the previous analysis, the distribution of overburden mining cracks is related to the caving and compaction characteristics of goaf, resulting in uneven distribution of gas in goaf. The drainage effect of different layout positions of high-drainage roadway is also different. The definition standard of drainage effect of highdrainage way is mainly manifested in the drainage concentration of high-drainage roadway and the gas concentration of upper corner. On the one hand, it is necessary to seek the 


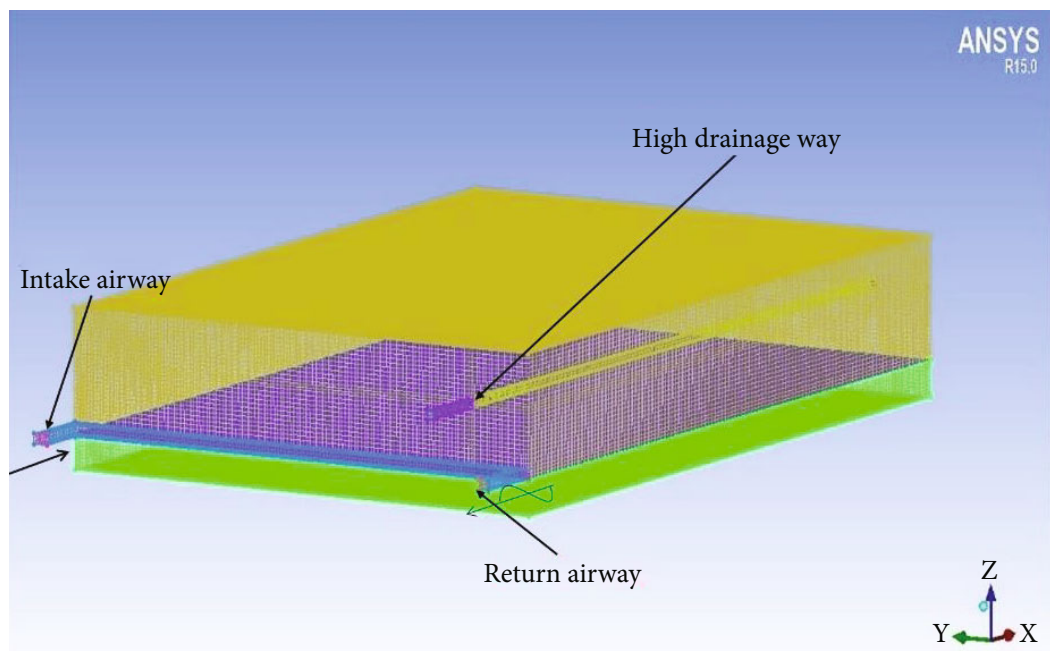

FIgURE 8: Plane diagram of U-shaped ventilation system grid.

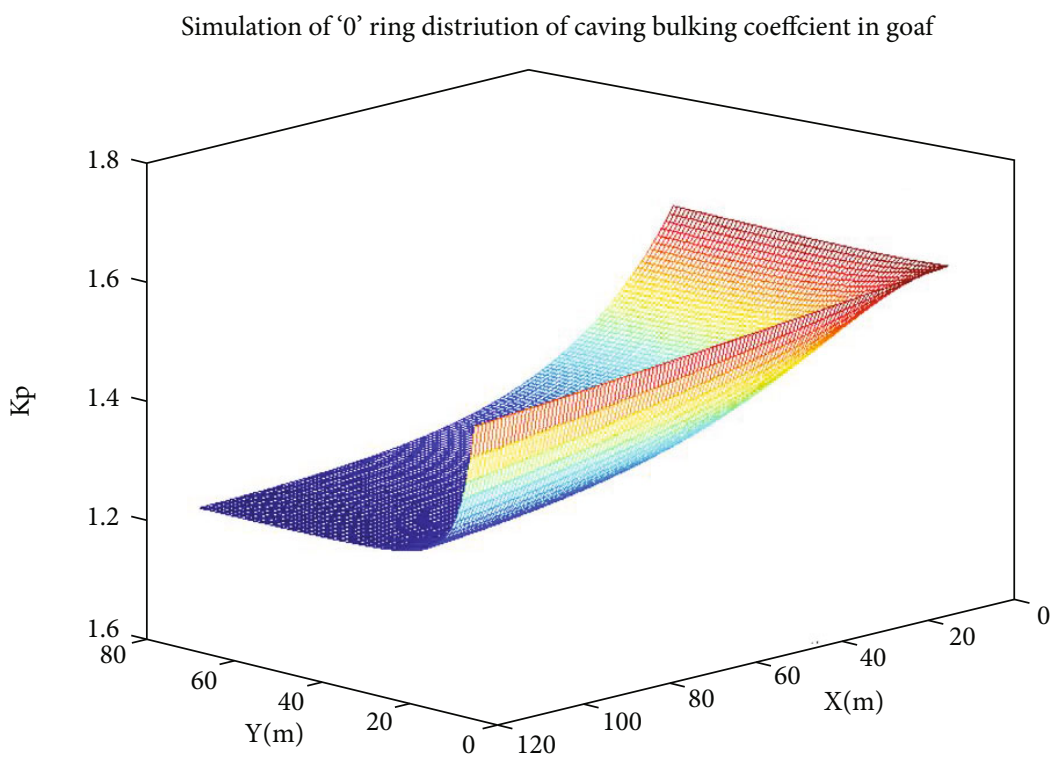

Figure 9: Division of bulking coefficient in goaf.

best position for gas extraction in high-drainage way, that is, the position where the concentration can reach the maximum value. On the other hand, it is necessary to examine the gas emission in the upper corner at different extraction positions, that is, the concentration in the upper corner is within a reasonable range and the lower the concentration is, the better the gas emission is.

According to the previous analysis, the reasonable extraction arrangement range is $15 \sim 36 \mathrm{~m}$ from the return airway, and the reasonable extraction vertical distance is from the upper part of the caving zone to the middle and lower part of the fracture zone. So this paper selects the simulation horizontal distance (from the return air lane outside) for $L=15 \mathrm{~m}, 25 \mathrm{~m}$, and $35 \mathrm{~m}$ and simulation vertical distance (from the coal seam floor) for $H=21 \mathrm{~m}, 28 \mathrm{~m}$, and $35 \mathrm{~m}$, a total of nine locations, see Table 3 .
TABle 3: Drainage scheme of high gas drainage gate.

\begin{tabular}{lcc}
\hline Position & Horizontal distance $(\mathrm{m})$ & Vertical distance $(\mathrm{m})$ \\
\hline 1 & 15 & 21 \\
2 & 15 & 28 \\
3 & 15 & 35 \\
4 & 25 & 21 \\
5 & 25 & 28 \\
6 & 25 & 35 \\
7 & 35 & 21 \\
8 & 35 & 28 \\
9 & 35 & 35 \\
\hline
\end{tabular}




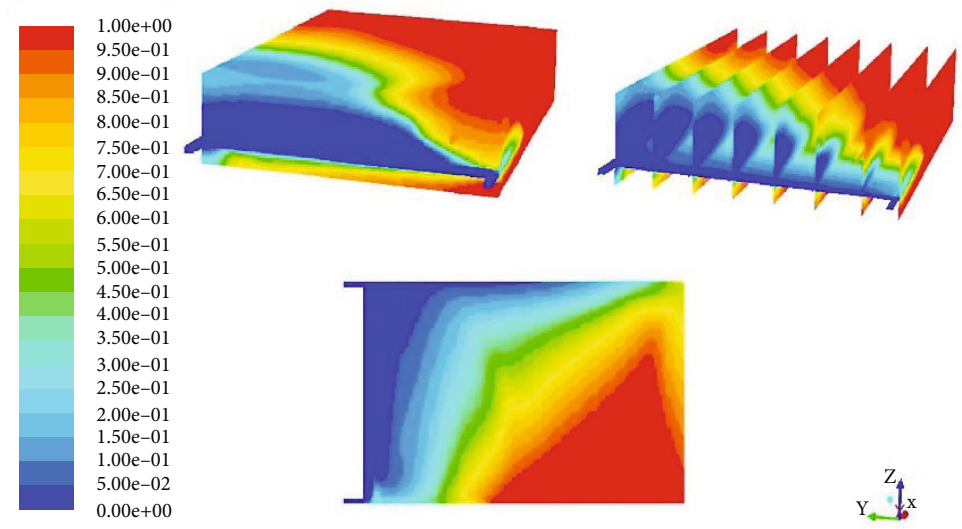

FIGURE 10: Goaf gas distribution without high gas drainage gate exhausting and mining. (a) Three-dimensional distribution map of goaf gas; (b) gas profile map in goaf; (c) gas profile map of goaf at $Z=3$.

\subsection{Simulation Results and Analysis}

4.3.1. The Simulation Effect under the Drainage Condition of No High-Drainage Way. The numerical simulation results show that the gas emission concentration in the upper corner reaches $24.2 \%$ without high-drainage roadway, which is far more than the allowable concentration value of the gas in the upper corner. It is difficult to produce the working face without reasonable extraction measures. Therefore, it is very necessary to arrange high-drainage way to extract goaf gas.

It can be seen from Figures $10(a)-10(c)$ that along the direction of vertical mining length, the gas concentration in the middle and upper part of the goaf extending to the deep part of the goaf continues to increase. The farther away from the working face, the greater the gas concentration is. In the inclination direction of the working face, affected by the intake air flow, the concentration of gas in the shallow part of the goaf on the return air side is significantly higher than that on the intake air side, and a large amount of highconcentration gas is concentrated in the rear of the upper corner. The main causes of this gas distribution are the wind pressure difference under the action of wind flow and the large expansion coefficient in the natural accumulation area of the caving zone near the working face, which makes the gas migrate and gather to the periphery of the goaf near the return air side.

\subsubsection{Simulation Effect of Extraction under Different Layout} Positions. The simulation results of high-drainage way at positions 1 9 are shown in Figures 11-19, where the goaf section and the central plane of high-drainage way are selected for each drainage location. The drainage results at positions 1 9 are shown in Table 4.

4.4. Simulation Result Analysis. In order to facilitate the comprehensive analysis of the simulation to obtain the results of each location, it is drawn into a scatter plot shown in Figure 20.

It can be seen from Table 2 and Figure 20 that the best extraction position is position No. 1 in extraction position No. 1, No. 2, and No. 3, the maximum extraction concentra- tion is $16.29 \%$, and the minimum gas concentration in the upper corner is $0.35 \%$. The extraction concentration of No. 2 extraction position is $16.13 \%$, and the gas concentration in the upper corner is $0.92 \%$, less than $1 \%$, which is also within a reasonable range. In the No. 5 , No. 6, and No. 7 extraction position, the best extraction position is No. 5 extraction position, the extraction concentration reached a maximum of $21.55 \%$, and the upper corner gas concentration is $0.60 \%$, in the safe range. In positions No. 7 , No. 8 , and No. 9, the maximum extraction concentration value of position No. 8 is $21.29 \%$, and the concentration value of the upper corner is relatively low at $1.14 \%$, but it has exceeded the provisions of coal mine safety regulations. By comparison, it is not difficult to find that the extraction concentration of No. 5 position is greater than that of other positions, which is the largest position of gas extraction in goaf, and also ensures that the gas emission concentration in the upper corner is within the safe range. Although the amount of gas extraction in position No. 1 is less than that in position No. 5, it has the best effect on gas control in the upper corner.

According to the simulation results, the influence trend of the change of horizontal and vertical extraction positions on the extraction effect of high extraction way is further analyzed.

4.4.1. Analysis of Results along Horizontal Distance of Extraction. The concentration change of high drainage roadway and gas emission concentration in the upper corner of 9 test drainage positions were grouped according to different vertical distances, and the broken line diagram was drawn as Figures 21-23.

It can be seen from Figure 21 that with the increase of the extraction horizontal distance on the $21 \mathrm{~m}$ vertical distance, the extraction concentration of the high-drainage way decreases continuously, and the extraction concentration is $15.79 \% \sim 16.29 \%$. On the contrary, the gas emission in the upper corner is increasing. This phenomenon is caused by the increase of extraction horizontal distance, and the high-drainage way is far away from the channel of 


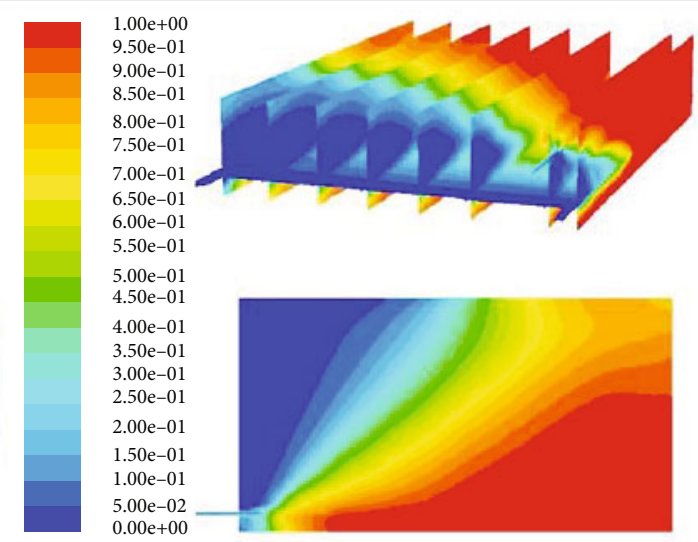

FIgURE 11: Gas distribution at position 1.

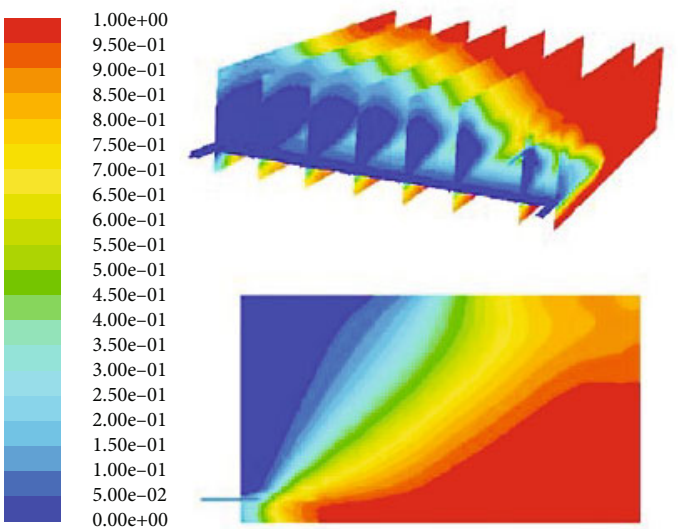

FIGURE 12: Gas distribution at position 2.

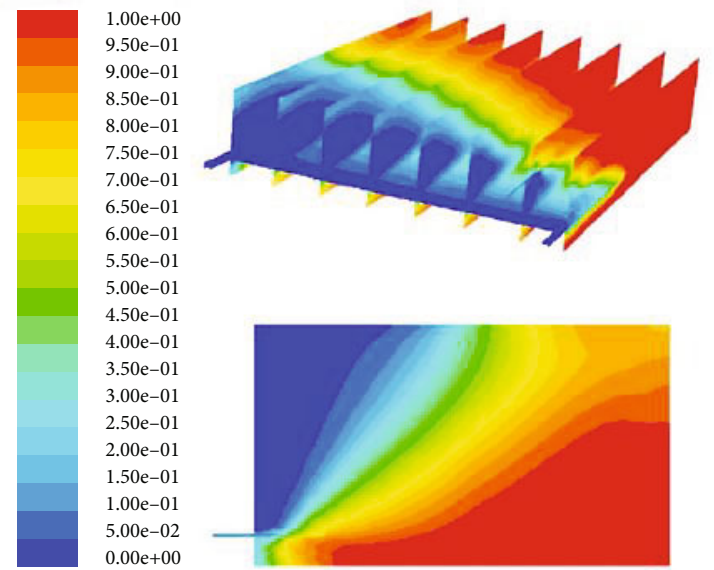

FIgURE 13: Gas distribution at position 3.

gas emission in goaf. From Figure 11, it can be seen that the two groups of high-drainage roadway with vertical distance of $28 \mathrm{~m}$ and $35 \mathrm{~m}$ have the same trend of drainage concen-

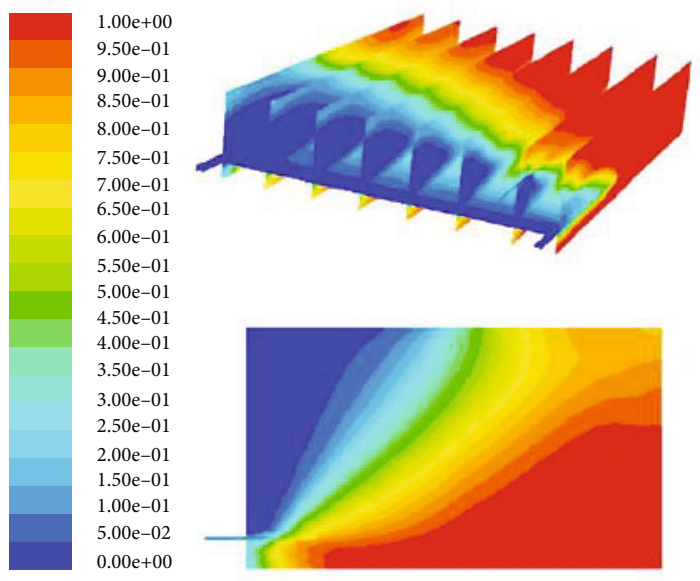

FIgURE 14: Gas distribution at position 4.

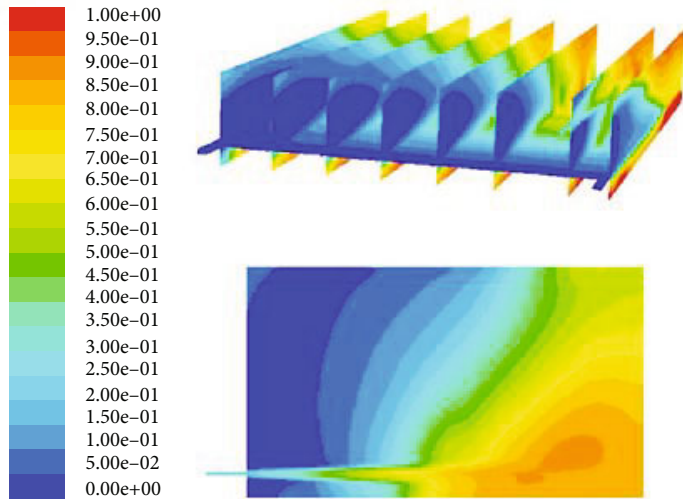

FIGURE 15: Gas distribution at position 5.

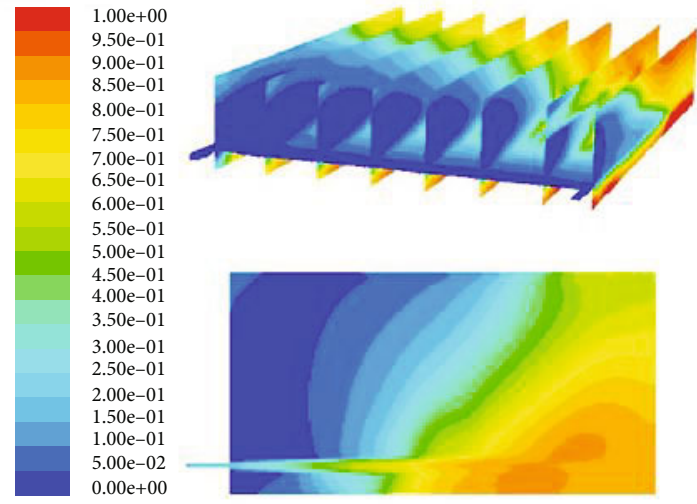

FIgURe 16: Gas distribution at position 6.

tration change, from low to high and then decrease, and the concentration value is between $20.32 \%$ and $21.55 \%$, which is significantly higher than that of the first group. Combined with Figure 11, the extraction of high-drainage 


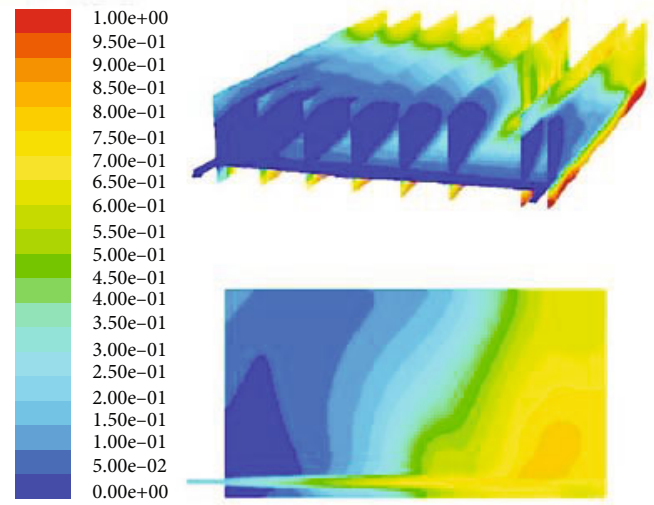

FIGURE 17: Gas distribution at position 7.

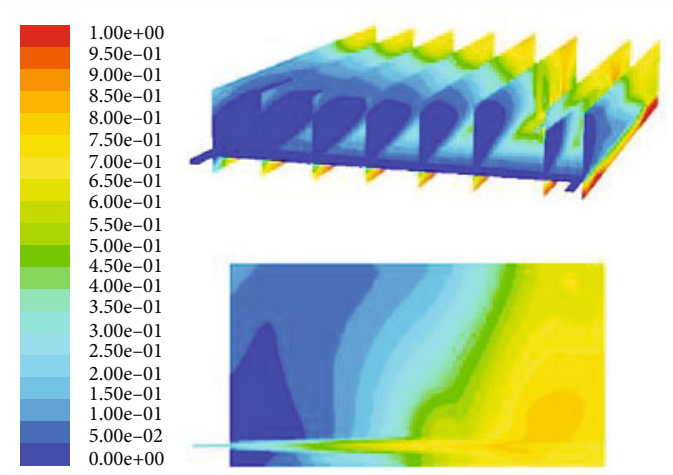

FIGURE 18: Gas distribution at position 8.

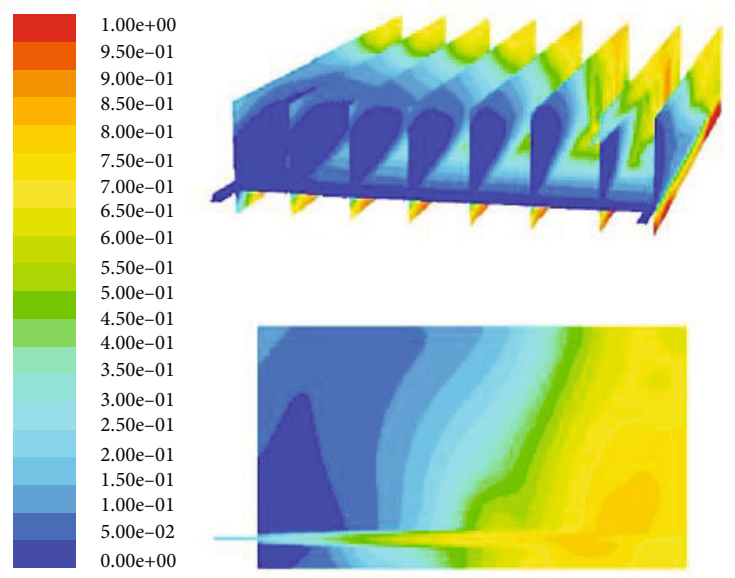

FIgUre 19: Gas distribution at position 9.

roadway is greatly affected by air flow. The air flow leaks into the goaf from the working face, and the leakage of fresh air flow brings gas into the high-drainage way under the action of high-drainage roadway extraction, resulting in low gas concentration.
TABLE 4: Simulation results from position 1 to position 9.

\begin{tabular}{lccc}
\hline Position & $\begin{array}{c}\text { Drainage } \\
\text { concentration } \\
\text { in high-drainage } \\
\text { way (\%) }\end{array}$ & $\begin{array}{c}\text { Gas } \\
\text { concentration } \\
\text { in upper } \\
\text { corner }(\%)\end{array}$ & $\begin{array}{c}\text { Pure quantity } \\
\text { of drainage } \\
\left(\mathrm{m}^{3} / \mathrm{min}\right)\end{array}$ \\
\hline 1 & 16.29 & 0.35 & 19.55 \\
2 & 16.13 & 0.92 & 19.36 \\
3 & 15.79 & 2.83 & 18.95 \\
4 & 20.97 & 0.97 & 25.16 \\
5 & 21.55 & 0.60 & 25.86 \\
6 & 21.32 & 1.27 & 25.58 \\
7 & 20.34 & 1.36 & 24.41 \\
8 & 21.29 & 1.14 & 25.55 \\
9 & 21.19 & 1.88 & 25.43 \\
\hline
\end{tabular}

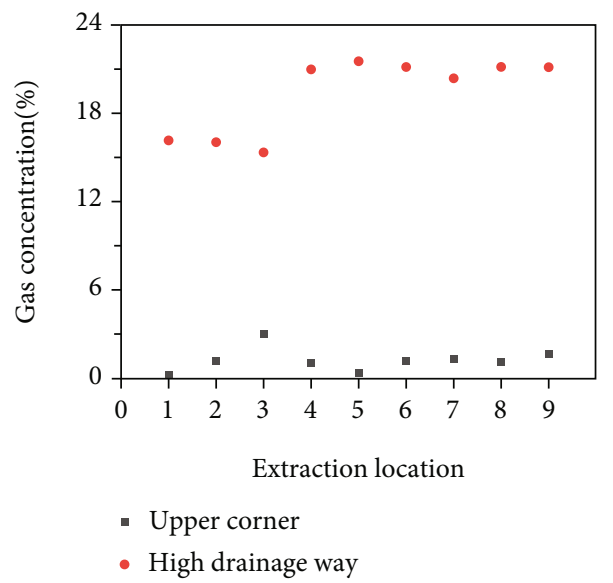

FIgURE 20: Simulation results scatter diagram from position 1 to position 9.

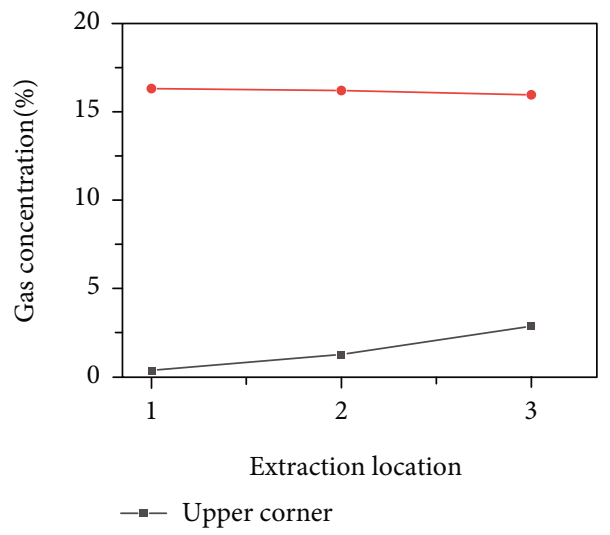

FIgURE 21: Simulation results change tendency from position 1 to position 3.

The variation trend of gas concentration in the upper corner of the two groups was the same, reaching the minimum $0.60 \%$ and $1.14 \%$ at position No. 5 and position No. 8. The main reason for this change is the different 


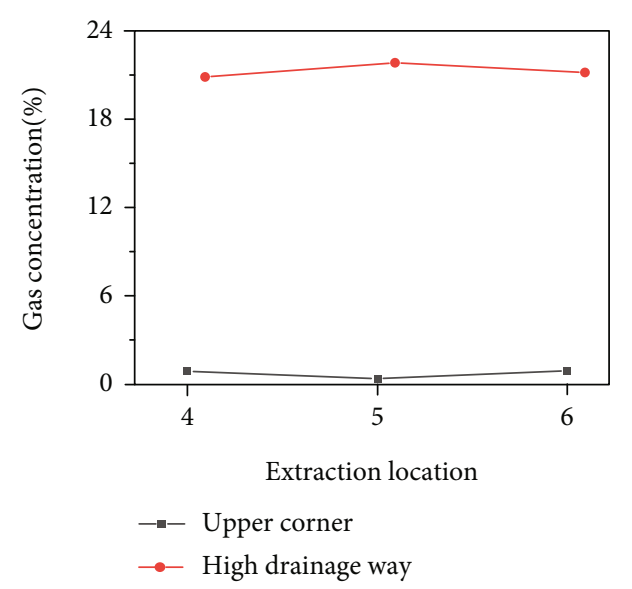

FIGURE 22: Simulation results change tendency from position 4 to position 6 .

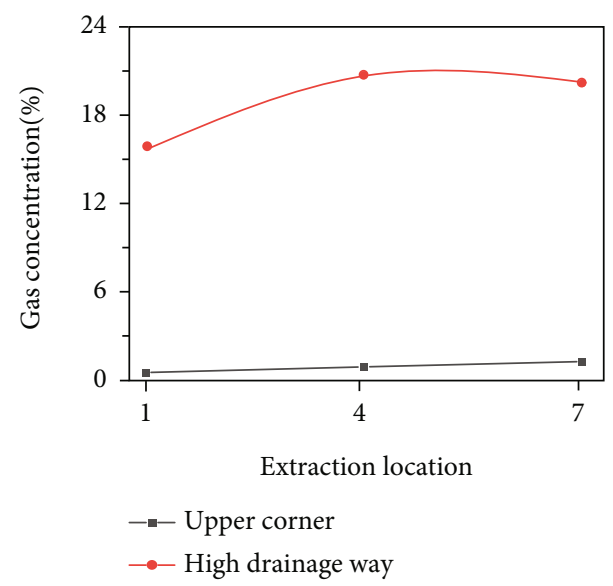

FIGURE 23: Simulation results change tendency from position 7 to position 9.

development degrees of fractures at the edge and middle of the "O" circle. The loose circle of mining-induced fractures is at the edge of the near return airway. Because the roof strata form a cantilever beam structure under the influence of coal pillar support, the fractures are not fully developed. At the edge of the gob side of the loose circle, the fractured rock block is compacted and closed under the action of rock load, which can also cause the blockage of gas flow. Therefore, the high drainage way has the best effect on gas interception and pulling in the middle of the loose circle, so the gas emission in the upper corner will also be reduced. Compared with Figures 11-19, it is not difficult to find that the change of gas in the deep goaf is not large at different extraction spacing positions on each vertical distance, which shows that under the effect of high-drainage way extraction, the same extraction vertical distance and different extraction spacing have little effect on the "pull" of gas in the deep goaf.

4.4.2. Analysis of Results along Vertical Distance of Extraction. The concentration change of high-drainage way and gas emission concentration in the upper corner of 9 test

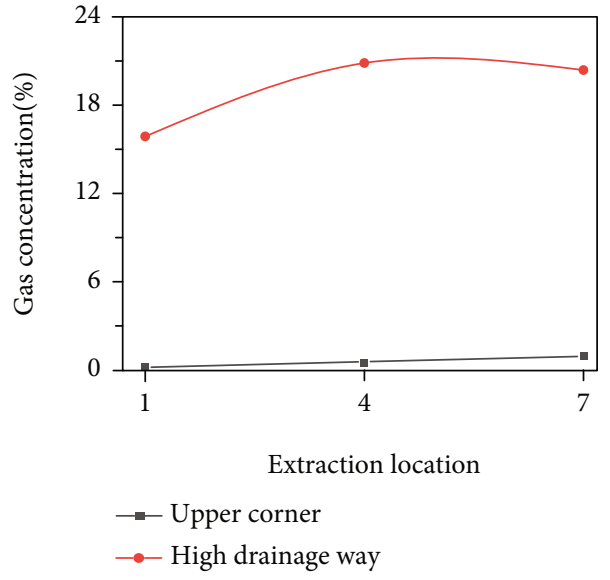

Figure 24: Simulation results change tendency at positions 1, 4, and 7 .

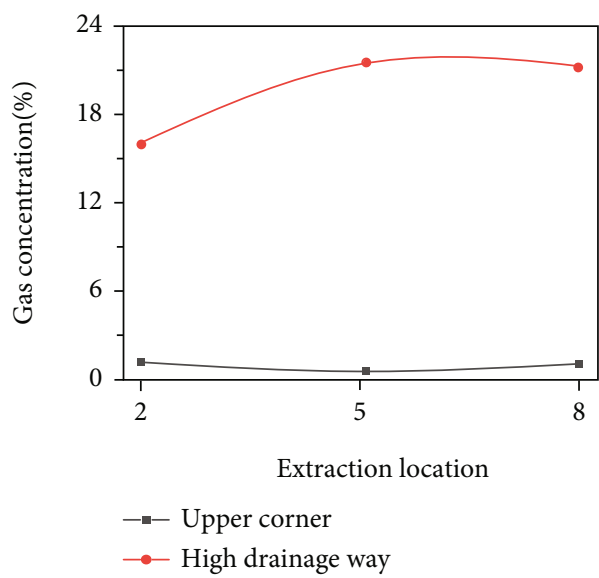

FIgURe 25: Simulation results change tendency at positions 2, 5, and 8 .

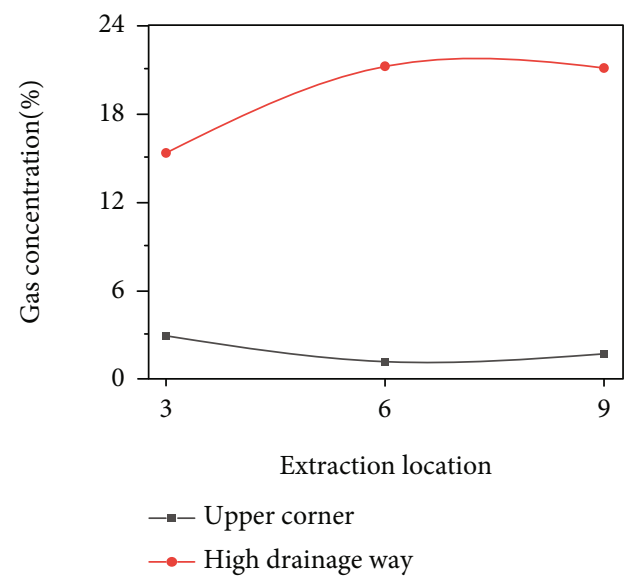

FIgURE 26: Simulation results change tendency at positions 3, 6, and 9 .

drainage positions were grouped according to different horizontal distances, and the broken line diagram is drawn as Figures 24-26. 


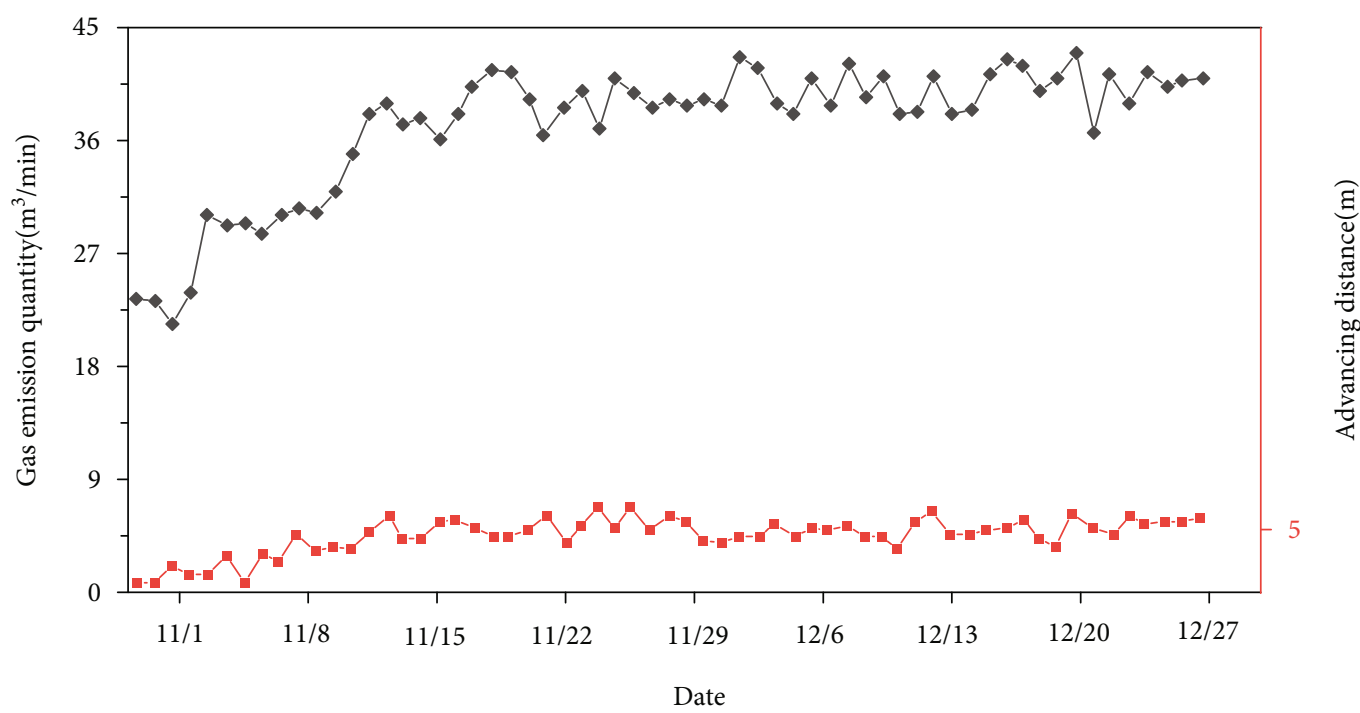

$\rightarrow$ Absolute gas emission of working face
$\rightarrow-$ Advancing distance of working face

FIGURE 27: Speed of working face and amount of gas emission.

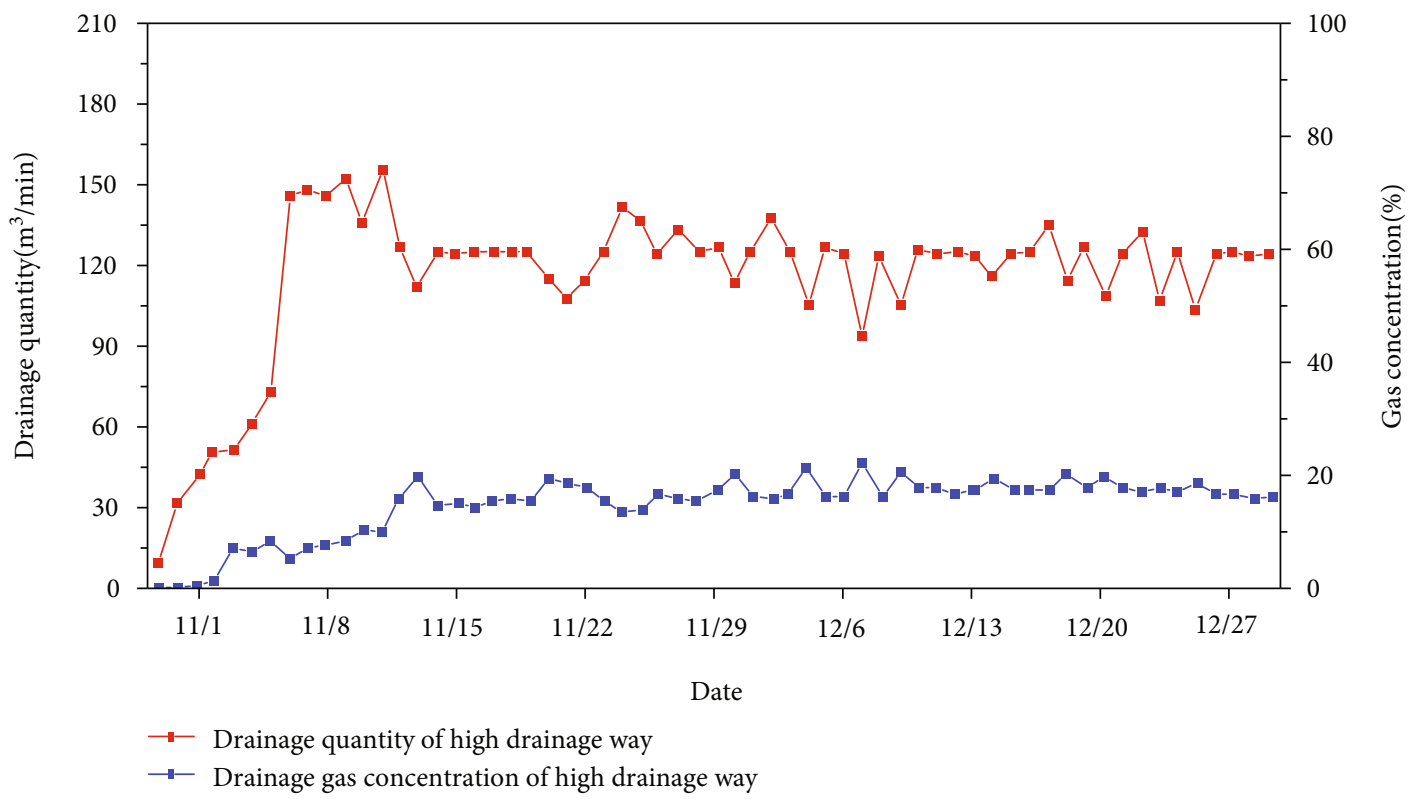

FIgURE 28: Drainage quantity and drainage gas concentration of high-drainage gate.

From Figure 21, it can be seen that at the positions horizontal distances of $15 \mathrm{~m}, 25 \mathrm{~m}$, and $35 \mathrm{~m}$, with the increase of extraction vertical distance, the gas extraction concentration of high-drainage way shows a trend of increasing first and then decreasing. The variation trend of gas concentration in the upper corner is different. At the position of $15 \mathrm{~m}$ horizontal distance, the vertical distance increases, and the gas concentration in the upper corner increases continuously. At the positions of $25 \mathrm{~m}$ and $35 \mathrm{~m}$ horizontal distance, the gas emission in the upper corner shows a trend from large to small and then increases. The main reason for the above changes is the influence of the development law of mining fractures. We further longitudinally compared Figures 11-19, respectively. It can be found that under the conditions of different extraction vertical distances of each group of horizontal distances, the distribution of deep gas concentration in the goaf was from low to high, and the concentration gradually decreased. This change trend is because the high-drainage roadway is arranged higher and higher, and the length of its depth into the goaf increases, thus effectively pulling the deep gas.

Therefore, the No. 5 position is in the most developed part of the mining fissure, in this position is also the goaf "O" ring and the vertical "gas" fissure ring intersection 


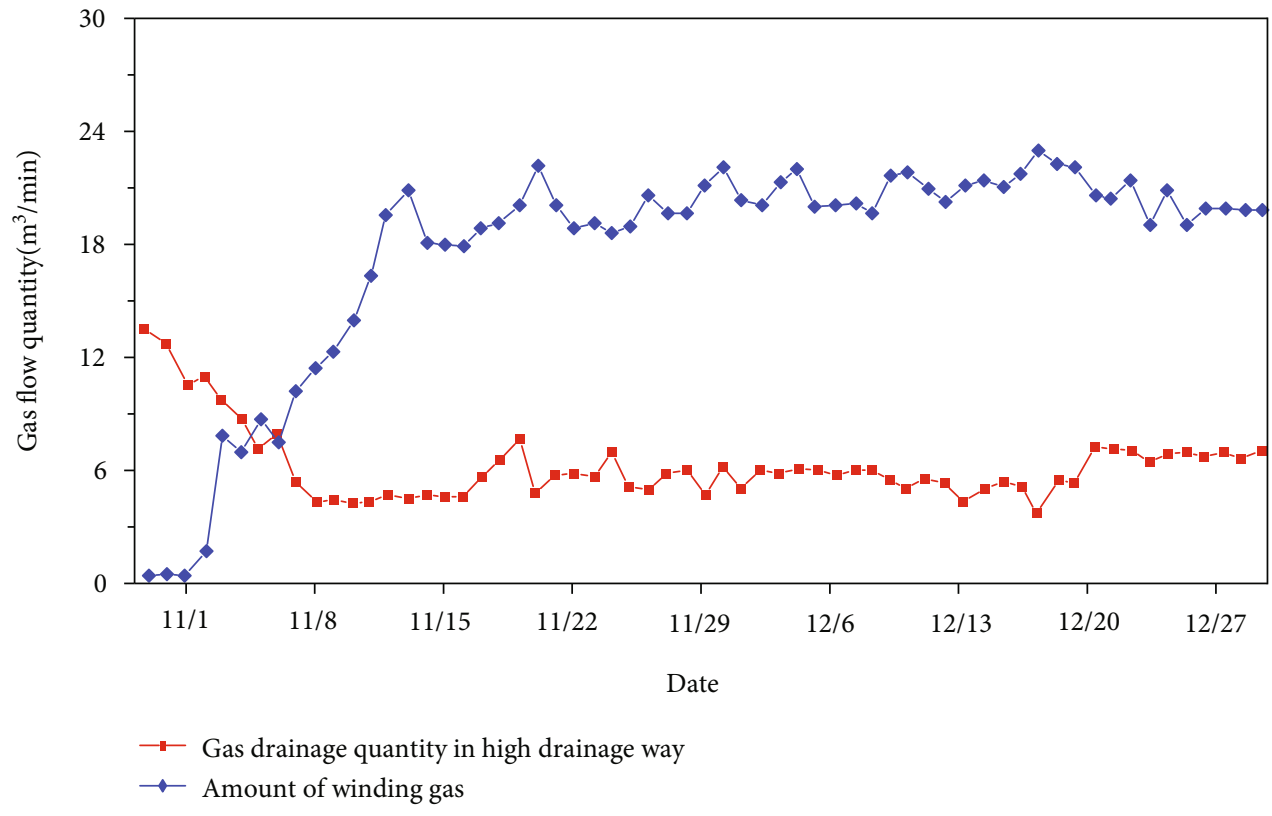

FIGURE 29: Drainage quantity of high-drainage gate and amount of winding gas.

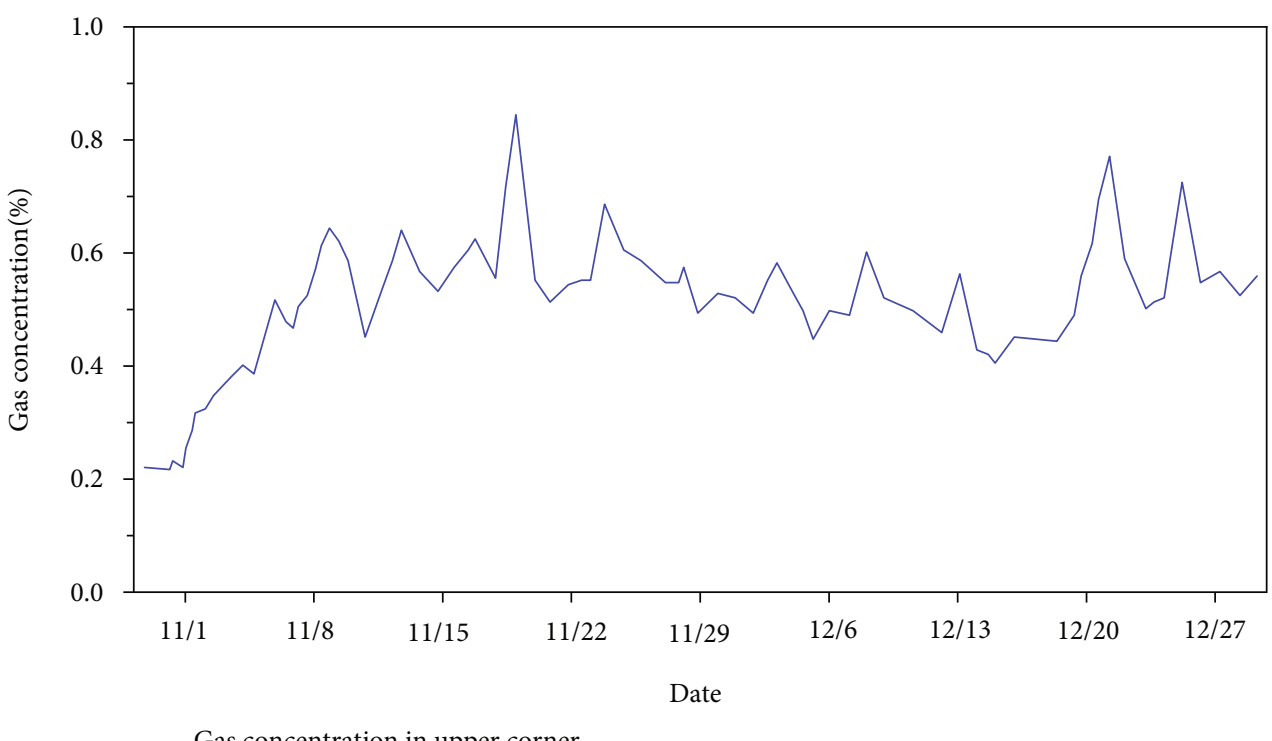

Figure 30: Gas concentration of upper corner.

position; the goaf into the working face gas can achieve the best closure extraction effect.

\section{Engineering Application}

The comprehensive research results of theoretical and numerical simulation show that the gas drainage effect is the best when the high-drainage way is arranged at the position of $15 \mathrm{~m}$ in horizontal distance and $21 \mathrm{~m}$ in vertical distance. Therefore, the actual high-drainage way is arranged according to this result.
This paper collected the drainage data from November 1 , 2014, to December 31, 2014. The relationship curve between the absolute gas emission and the advancing speed of the working face is shown in Figure 27. In the early stage of working face mining, the absolute gas emission reached $23 \mathrm{~m}^{3} / \mathrm{min}$ (the sum of air displacement and borehole extraction), and the gas emission increased with the advance of working face.

From the analysis of Figures 28-31, it can be seen that during the initial mining of the working face, the extraction volume and extraction concentration of the high-drainage way increase with the advancement of the working face, which proves that it is precise because of the early 


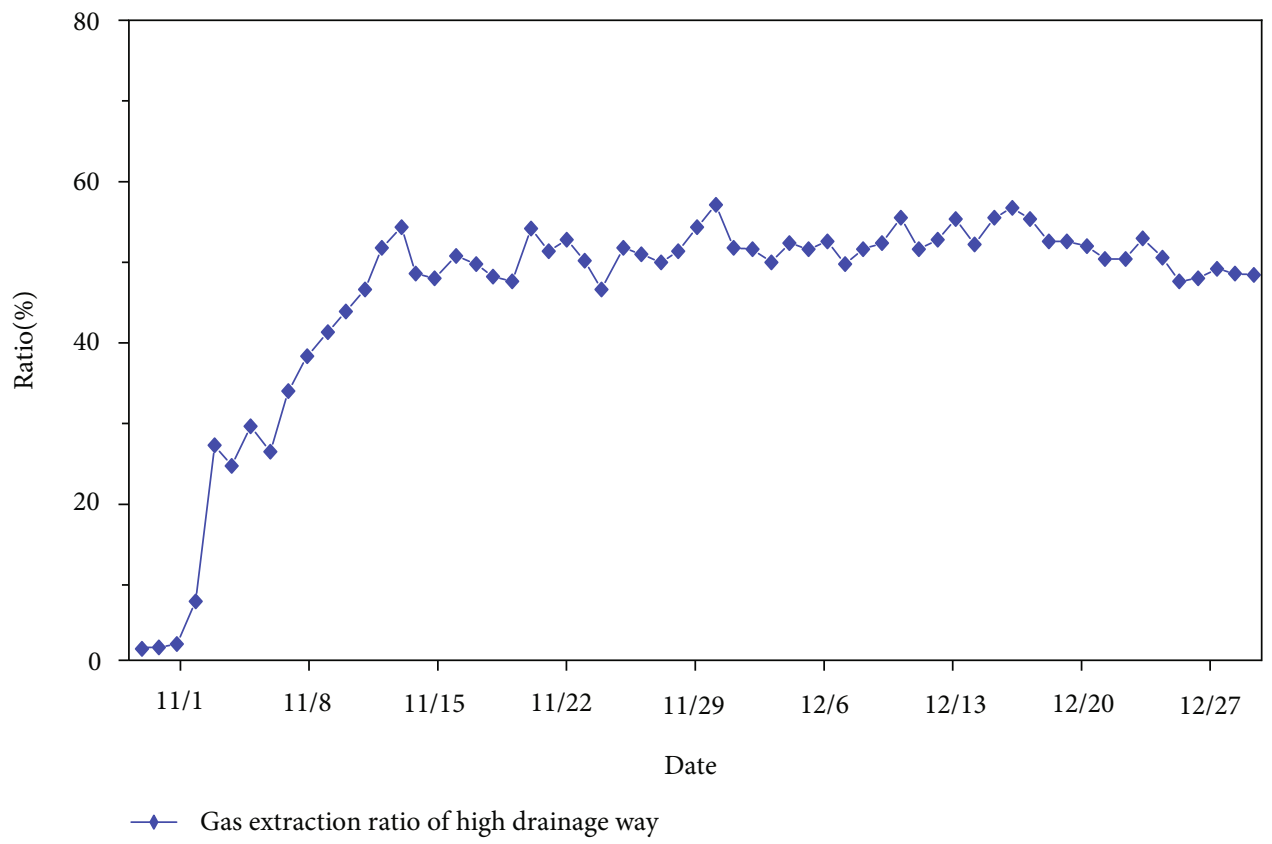

Figure 31: Gas extraction ratio of high-drainage way.

downregulation design of the high-drainage way that the high-drainage way is quickly put into extraction. Before and after November 7, the working face completed the cycle transition from mining height to $6 \mathrm{~m}$, and the immediate roof fell for the first time. The flow value of high-level pumping roadway reached $140 \mathrm{~m}^{3} / \mathrm{min}$, and the concentration value decreased by $7 \%$ from $9 \%$, but the extraction purity increased to $9.4 \mathrm{~m}^{3} / \mathrm{min}$. During the initial mining adjustment, a large number of coal caving goaf, releasing more gas, the upper corner gas concentration increased slightly.

After the end of the initial mining period, the working face maintained an average advancing degree of $5.5 \mathrm{~m}$. The average absolute gas emission of the working face reached $39.28 \mathrm{~m}^{3} / \mathrm{min}$. The drainage volume of the high-drainage way was $16.4 \sim 23.3 \mathrm{~m}^{3} / \mathrm{min}$, and the average drainage volume was $20.45 \mathrm{~m}^{3} / \mathrm{min}$. The drainage volume of the highdrainage way accounted for $52.1 \%$ of the gas emission. The average extraction concentration of high-drainage way is $17.6 \%$, and the average gas concentration in the upper corner is $0.52 \%$, which is close to the numerical simulation results, proving that the numerical simulation model is reliable. The average gas ventilation volume is $7.1 \mathrm{~m}^{3} / \mathrm{min}$, and the average gas extraction rate is $82.2 \%$.

Comprehensive use of theoretical analysis, field investigation, and numerical simulation method to determine the 206 working face roof inclined high-drainage way drainage layout prevents the occurrence of gas overrun in the upper corner, ensures the safe and efficient mining of the working face, improves the gas drainage rate of the working face, and achieves the expected effect.

\section{Conclusions}

In this paper, the 206 working face of Tingnan Coal Mine is taken as the engineering practice, and the reasonable posi- tion of the roof inclined high-drainage way is studied by combining theoretical calculation, numerical simulation, and field test. The following results are obtained:

(1) Based on the key layer theory and rock masonry beam theory, the deformation and failure laws of "three zones" of vertical distribution and three zones of transverse distribution of goaf rock are systematically studied. Combined with the gas migration and distribution law of mining fracture, the vertical and horizontal separation of working face and the distribution characteristics of "O" circle of fracture are analyzed; the reasonable theoretical range of highdrainage roadway layout with horizontal distance of $15 \sim 36 \mathrm{~m}$ and vertical distance of $21 \sim 40 \mathrm{~m}$ is determined, which provides the basis and reference for the development of numerical simulation

(2) The numerical simulation model of high-drainage way drainage was established for 206 working face. Through the numerical simulation, it was obtained that the drainage horizontal distance of $15 \mathrm{~m}$ and the vertical distance of $21 \mathrm{~m}$ were the layout positions of high-drainage roadway with the best gas control effect in the upper corner. The extraction horizontal distance of $25 \mathrm{~m}$ and the vertical distance of $26 \mathrm{~m}$ are the optimal positions for the best extraction effect and gas control in the upper corner

(3) The drainage application of high-drainage roadway was monitored. The average absolute gas emission of working face was $39.28 \mathrm{~m}^{3} / \mathrm{min}$, the drainage volume of high-drainage roadway was $16.4 \sim 23.3 \mathrm{~m}^{3} /$ $\mathrm{min}$, and the average drainage volume was $20.45 \mathrm{~m}^{3} / \mathrm{min}$. The drainage volume of highdrainage roadway accounted for $52.1 \%$ of the gas 
emission. The average gas concentration in the upper corner is $0.52 \%$, which is close to the numerical simulation results. The average gas drainage rate of the working face is $82.2 \%$. The drainage arrangement of 206 high-drainage roadway eliminates the occurrence of gas overrun in the upper corner, ensures the safe and efficient mining of the working face, improves the gas drainage rate of the working face, and achieves the expected effect

\section{Data Availability}

The data used to support the findings of this study are available from the corresponding author upon request.

\section{Conflicts of Interest}

The authors declare that they have no known competing financial interests or personal relationships that could have appeared to influence the work reported in this paper.

\section{Acknowledgments}

This research was funded by the Natural Science Foundation of China (52174188).

\section{References}

[1] A. Liu, S. Liu, P. Liu, and K. Wang, "Water sorption on coal: effects of oxygen containing function groups and pore structure," International Journal of Coal Science and Technology, vol. 2, pp. 1-20, 2021.

[2] P. Liu, X. Zhou, and Q. Qian, “Experimental investigation of rigid confinement effects of radial strain on dynamic mechanical properties and failure modes of concrete," International Journal of Mining Science and Technology, vol. 31, no. 5, pp. 939-951, 2021.

[3] H. Wang, X. Fang, F. Du et al., “Three-dimensional distribution and oxidation degree analysis of coal gangue dump fire area: a case study," Science of the Total Environment, vol. 772, article 145606, 2021.

[4] J. Zhou, C. Chen, M. Wang, and M. Khandelwal, "Proposing a novel comprehensive evaluation model for the coal burst liability in underground coal mines considering uncertainty factors," International Journal of Mining Science and Technology, vol. 31, no. 5, pp. 799-812, 2021.

[5] W. You, F. Dai, Y. Liu, H. Du, and R. Jiang, "Investigation of the influence of intermediate principal stress on the dynamic responses of rocks subjected to true triaxial stress state," International Journal of Mining Science and Technology, vol. 31, no. 5, pp. 913-926, 2021.

[6] F. Du, K. Wang, G. Wang, Y. Huang, and L. Yi, “The mechanism of damage in gas-bearing coal-rock combination bodies and gas seepage in coals," Energy Sources, Part A: Recovery, Utilization, and Environmental Effects, vol. 43, no. 10, pp. 1181-1201, 2021.

[7] X. Chen, L. Zheng, Y. Jiang, and C. Jiang, "Transformation of minerals at the boundary of magma-coal contact zone: case study from Wolonghu coal mine, Huaibei Coalfield, China," International Journal of Coal Science \& Technology, vol. 8, no. 1, pp. 168-175, 2021.
[8] Y. Tang, R. Li, and S. Wang, "Research progress and prospects of coal petrology and coal quality in China," International Journal of Coal Science \& Technology, vol. 7, no. 2, pp. 273287, 2020.

[9] D. Guo, P. Lv, J. Zhao, and C. Zhang, "Research progress on permeability improvement mechanisms and technologies of coalbed deep-hole cumulative blasting," International Journal of Coal Science and Technology, vol. 7, no. 2, pp. 329-336, 2020.

[10] H. Wang, B. Tan, Z. Shao, Y. Guo, Z. Zhang, and C. Xu, "Influence of different content of $\mathrm{FeS}_{2}$ on spontaneous combustion characteristics of coal," Fuel, vol. 288, article 119582, 2021.

[11] K. Wang and F. Du, "Coal-gas compound dynamic disasters in China: a review," Process Safety and Environmental Protection, vol. 133, pp. 1-17, 2020.

[12] F. Gong, Y. Wang, Z. Wang, J. Pan, S. Luo, and S. Luo, “A new criterion of coal burst proneness based on the residual elastic energy index," International Journal of Mining Science and Technology, vol. 31, no. 4, pp. 553-563, 2021.

[13] C. Pan, B. W. Xia, B. Yu, P. Yu, Y. Luo, and Y. Gao, "Determination of the key parameters of high-position hard roofs for vertical-well stratified fracturing to release strong ground pressure behavior in extra-thick coal seam mining," Energy science \& Engineering, vol. 8, no. 6, pp. 2216-2238, 2020.

[14] G. J. Hasenfus, K. L. Johnson, and D. W. H. Su, “A hydrogeomechanical study of overburden aquifer response to longwall mining," Proceedings of 7th International Conference on Ground Control in Mining, Morgantown, vol. 7, 1988.

[15] M. G. Qian, P. W. Shi, and J. L. Xu, Mining Pressure and Strata Control, China University of Mining and Technology Press, 2010.

[16] H. F. Lin, Study on the Law of Mining-Induced Fracture Evolution of Overlying Strata and Relieved Methane Delivery and Its Engineering Application in Fully-Mechanized Top Coal Caving, Xi'an university of science and technology, 2009.

[17] W. Zhang, Study on the Gas Seepage Law in Gob and It's Numerical Simulation, Xi'an university of science and technology, 2008.

[18] Z. X. LI, G. YI, J. G. WU, D. GUO, C. J. ZHAO, and D. ZHAO, "Study on spontaneous combustion distribution pf goaf based on the ' $\mathrm{O}$ ' type risked falling and non-uniform oxygen," Journal of China Coal Society, vol. 37, pp. 484-489, 2012.

[19] L. Yuan, "Gas control technology and practice in Huainan mining area," Coal Science and Technology, vol. 1, pp. 7-11, 2000.

[20] J. Liu, Z. G. Liu, M. Shi, and F. Cai, "Technology of gas predrainage with deep borehole pre-cracking blasting for gateway rapid excavation in seam with outburst," Coal Science and Technology, vol. 8, pp. 45-48, 2008.

[21] Y.-k. CHEN, G.-l. DAI, D.-q. WANG, W.-d. TANG, W. U. Lei, and Y. LIU, "Study on pressure released gas control technology of upper protective seam mining," Coal Science and Technology, vol. 41, pp. 77-80, 2013.

[22] J. F. Lou, "Research on the deformation mechanism and the location optimization of high-level entry for gas extraction," China University of Mining and Technology, Xuzhou, 2008.

[23] M. G. Qian and J. L. Xu, "Advance in the key strata theory of mining rockmass," Journal of China University of Mining \& Technology, vol. 1, pp. 25-29, 2000. 